Article

\title{
Highly Sensitive UV Photodiode Composed of $\beta$-Polyfluorene/YZnO Nanorod Organic-Inorganic Hybrid Heterostructure
}

\author{
Youngmin Lee ${ }^{1}\left(\mathbb{D}\right.$, Soo Youn Kim ${ }^{2} \mathbb{(}$, Deuk Young Kim ${ }^{1,2}$ and Sejoon Lee ${ }^{1,2, * \mathbb{C}}$ \\ 1 Quantum-Functional Semiconductor Research Center, Dongguk University-Seoul, Seoul 04623, Korea; \\ ymlee@dongguk.edu (Y.L.); dykim@dongguk.edu (D.Y.K.) \\ 2 Division of Physics \& Semiconductor Science, Dongguk University-Seoul, Seoul 04623, Korea; \\ sooyoun@dgu.ac.kr \\ * Correspondence: sejoon@dongguk.edu; Tel.: +82-2-2260-3946; Fax: +82-2-2260-3945
}

Received: 6 July 2020; Accepted: 25 July 2020; Published: 29 July 2020

\begin{abstract}
The highly sensitive ultra-violet (UV) photodiode was demonstrated on the organic-inorganic hybrid heterostructure of $\beta$-phase p-type polyfluorene (PFO)/n-type yttrium-doped zinc oxide nanorods (YZO-NRs). The device was fabricated through a simple fabrication technique of $\beta$-phase PFO coating onto YZO-NRs that had been directly grown on graphene by the hydrothermal synthesis method. Under UV illumination $(\lambda=365 \mathrm{~nm})$, the device clearly showed excellent photoresponse characteristics (e.g., high quantum efficiency $\sim 690 \%$, high photodetectivity $\sim 3.34 \times 10^{12} \mathrm{~cm} \cdot \mathrm{Hz}^{1 / 2} \cdot \mathrm{W}^{-1}$, and fast response time $\sim 0.17 \mathrm{~s}$ ). Furthermore, the ratio of the photo current-to-dark current exceeds $10^{3}$ even under UV illumination with a small optical power density of $0.6 \mathrm{~mW} / \mathrm{cm}^{2}$. We attribute such superb photoresponse characteristics to both $Y$ incorporation into YZO-NRs and conformation of $\beta$-phase PFO. Namely, Y dopants could effectively reduce surface states at YZO-NRs, and $\beta$-phase PFO might increase the photocarrier conductivity in PFO. The results suggest that the $\beta$-phase $\mathrm{p}-\mathrm{PFO} / \mathrm{n}$-YZO-NR hybrid heterostructure holds promise for high-performance UV photodetectors.
\end{abstract}

Keywords: Y-doped zinc oxide; nanorod; polyfluorene; hybrid structure; heterojunction; photodiode

\section{Introduction}

For the last two decades, $\mathrm{ZnO}$ nanostructures have garnered substantial attention because of their prodigious potential for blue and ultra-violet (UV) optoelectronic devices [1-6]. Among various nanostructures, 1-dimensional $\mathrm{ZnO}$ (e.g., nanorod [7,8], nanoneedle [9,10], nanopillar [11,12], etc.) is one of the most attractive nanoarchitectures due to its short pathway for carrier transport [13], high surface-to-volume ratio for photon collection [14], and low exciton-phonon coupling strength [15]. In recent years, furthermore, extra foreign element-doped $\mathrm{ZnO}$ nanorods (NRs) have been of particular interest because extra foreign dopants could improve the electrical and the optical properties of $\mathrm{ZnO}$ [16-24]. For instance, we recently reported that Y-doping led to the reduction of oxygen-related defects in $\mathrm{YZnO}$ (YZO) [22,23]; hence, the electrical conductivity and the excitonic emission properties could be improved by $Y$ doping into YZO films $[19,20]$ and n-type yttrium-doped zinc oxide nanorods (YZO-NRs) [21-23], respectively.

In addition, $\mathrm{ZnO}$ is highly compatible with other materials and it can be categorized into two different aspects. One is an availability for the easy growth of single-crystalline $\mathrm{ZnO}$; i.e., high-quality $\mathrm{ZnO}$ can be effectively grown on every substrate such as $\mathrm{Si}$ [25,26], GaN [27,28], glass [29], plastic substrates [30,31], and graphene [32-34]. Among various possible substrates, particularly, 
2-dimensional graphene offers a special benefit because high-quality $\mathrm{ZnO}$ could be directly grown on graphene due to its honeycomb lattices, which act as the seed sites for nucleation of wurtzite $\mathrm{ZnO}$ [33-35]. The other is that $\mathrm{ZnO}$ could be hybridized with various organic semiconductors. This allows us to form novel functional device architectures that can open up new avenues toward various applications using $\mathrm{ZnO}$-based inorganic-organic hybrid heterostructures. For instance, multi-level memory cells [36,37], high speed barristors [38], color-tunable light-emitting diodes [18,39], and color-dependent photodiodes [40] are typical examples of $\mathrm{ZnO}$-based inorganic-organic hybrid electronic and optoelectronic devices. Among various organic semiconductors, $\beta$-phase polyfluorene (PFO) is of ample interest particularly for optoelectronic device applications because of its wide band-gap energy and good processability [41-43]. Furthermore, since $\beta$-phase PFO has a higher charge-carrier mobility than other organic semiconductors [44], many researchers have been devoted to demonstrating highly efficient solid-state light-emitting devices using the inorganic-organic hybrid heterostructure of $\mathrm{ZnO} / \mathrm{PFO}$ [45-49]. To our best awareness, however, $\mathrm{ZnO} / \mathrm{PFO}-$ based light-sensing photodiodes (PDs) have rarely been investigated [50-52] in spite of great potential for highly sensitive UV detection (e.g., space exploration, environmental monitoring, flame detection, defense warning, medical equipment, security communication systems, etc. [1-4]).

Aiming at demonstrating the high-performance UV PDs by using PFO and YZO-NRs, we have therefore investigated the fabrication and the characterization of the $\beta$-phase p-type PFO/n-type YZO-NRs organic-inorganic hybrid heterojunction PDs. The hybrid PDs were effectively fabricated by spin-coating of $\beta$-phase PFO onto YZO-NRs that had been directly grown on graphene by the hydrothermal synthesis method. The devices exhibited excellent UV photoresponse properties even under low-power UV illumination. Herein, we report on experimental data obtained from systematic analyses of the material-to-device characteristics.

\section{Experimental Section}

\subsection{Preparation of Graphene/SiO $\mathrm{O}_{2} \mathrm{Si}$ Substrate}

Figure 1 displays the schematic illustrations of the device fabrication procedure. As an initial task, we prepared the graphene/ $\mathrm{SiO}_{2} / \mathrm{Si}$ substrate for the direct growth of high-quality YZO-NRs. First, the single-layer graphene sheet was grown on $\mathrm{Cu}$ foil by chemical vapor deposition [53], and transferred onto the $\mathrm{SiO}_{2} / \mathrm{Si}$ substrate through the typical transfer method using poly(methyl methacrylate) (Figure 1a). Then, the substrate was subsequently annealed at $280{ }^{\circ} \mathrm{C}$ for $10 \mathrm{~min}$ in vacuum to eliminate residual chemical contaminants on the graphene surface [32].

\subsection{Direct Growth of YZO-NRs on Graphene}

The hexagonal YZO-NRs were directly grown on graphene via the seedless hydrothermal method (Figure $1 \mathrm{~b}$ ). First, the aqueous solution of $\mathrm{YZO}(0.1 \mathrm{M})$ was prepared by mixing zinc nitrate hexahydrate $\left(\mathrm{Zn}\left(\mathrm{NO}_{3}\right)_{2} \cdot 6 \mathrm{H}_{2} \mathrm{O}\right)$, hexamethylenetetramine $\left(\mathrm{C}_{6} \mathrm{H}_{12} \mathrm{~N}_{4}\right)$, and yttrium acetate hydrate $\left(\mathrm{Y}\left(\mathrm{CH}_{3} \mathrm{COO}\right)_{3} \cdot \mathrm{H}_{2} \mathrm{O}\right)$ in deionized (DI) water $(35 \mathrm{~mL})$. Here, we note that the molar fraction ratio of $\mathrm{Zn}: \mathrm{Y}$ was varied from $99 \%: 1 \%$ to $95 \%: 5 \%$ to investigate the effects of $Y$ contents on both the material and the device characteristics. After transferring the prepared solution into the autoclave, the YZO-NRs were hydrothermally synthesized at $85^{\circ} \mathrm{C}$ for $8 \mathrm{~h}$. Thereafter, the samples were rinsed in DI water to clean the precipitates off the surface, and cured at $300^{\circ} \mathrm{C}$ for $10 \mathrm{~min}$ in an electric oven. Finally, to improve the crystal quality of $Y Z O$, the samples were annealed at $500^{\circ} \mathrm{C}$ for $1 \mathrm{~min}$ in vacuum by rapid thermal annealing.

\subsection{Fabrication of PFO/YZO-NR PDs}

The $\mathrm{p}-\mathrm{PFO} / \mathrm{n}-\mathrm{YZO}-\mathrm{NR}$ organic-inorganic hybrid heterostructures were fabricated by spin-coating of PFO (poly $\left(9,9^{\prime}\right.$-dioctyfluorene) onto YZO-NRs (Figure 1c). First, PFO (50 mg) was dissolved in chloroform $(1 \mathrm{~mL})$. The mixture solution was coated on the YZO-NR samples at a spinning speed of 
$1000 \mathrm{rpm}$; then, the samples were heated at $120^{\circ} \mathrm{C}$ for $10 \mathrm{~min}$ in an electrical oven to transform the casted PFO layer into $\beta$-phase. In order to enhance the hole carrier injection probability in the hybrid structure, additionally, we spin-coated the hole injection layer of PEDOT:PSS on the top of PFO at $4000 \mathrm{rpm}$. After dehydrating the samples at $110{ }^{\circ} \mathrm{C}$ for $40 \mathrm{~min}$, finally, the Ohmic electrodes of $\mathrm{Al}$ and Au were patterned on YZO and PEDOT:PSS, respectively, by thermal evaporation (Figure 1d). We here note that the active area for photon collection was designed to be $1 \mathrm{~cm}^{2}$.

(a)

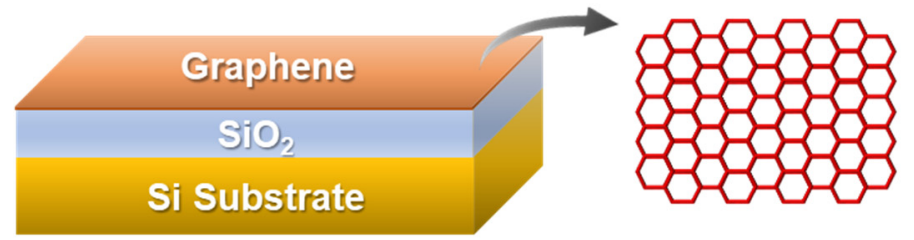

(b)

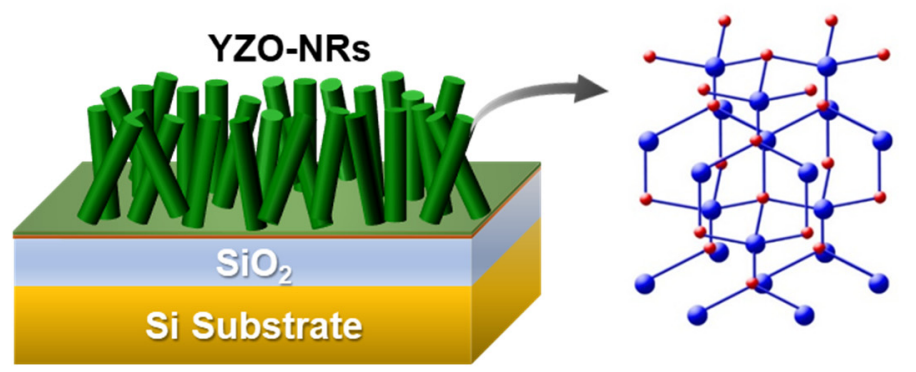

(c)

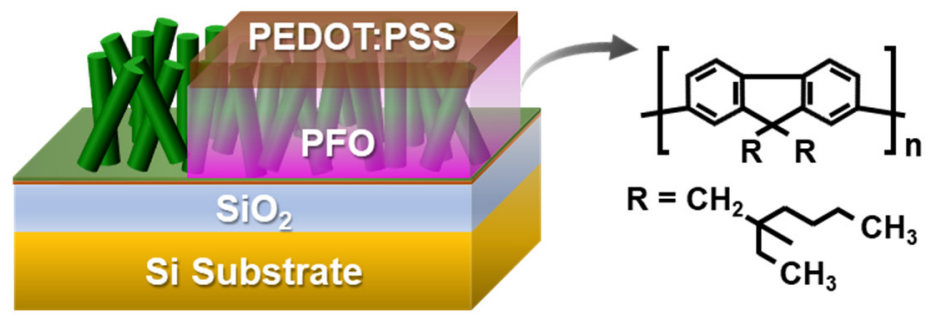

(d)

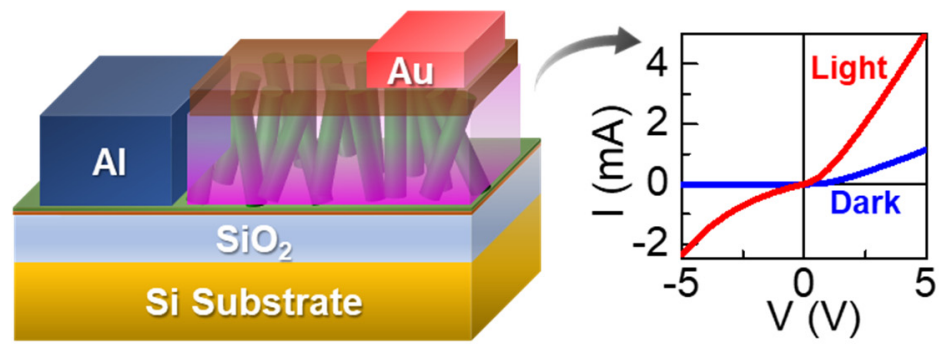

Figure 1. Experimental procedures for the fabrication of the PFO/YZO-NR PD: (a) graphene transfer onto the $\mathrm{SiO}_{2} / \mathrm{Si}$ substrate, (b) growth of YZO-NRs on graphene by the hydrothermal method. (c) spin-coating of PFO and PEDOT:PSS on YZO-NRs, and (d) Formation of Ohmic electrodes via $\mathrm{Al}$ and $\mathrm{Au}$ evaporation. The right-hand-side insets of $(\mathbf{a}-\mathbf{d})$ represent the honeycomb lattices of graphene, the wurtzite lattices of $\mathrm{YZO}$, the molecule chain structure of $\mathrm{PFO}$, and I-V characteristic curve of the PFO/YZO-NR PD, respectively. YZO-NRs: n-type yttrium-doped zinc oxide nanorods; PD: photodiodes; PFO: polyfluorene.

\subsection{Characterization of Materials and Devices}

The topographic properties of YZO-NRs and PFO were monitored by scanning electron microscopy (SEM) using an FE SEM XL-30 system (Phillips, Eindhoven, The Netherlands), and the optical properties of the samples were characterized by photoluminescence (PL) spectroscopy using a home-built PL system equipped with an excitation source of the He-Cd laser $(\lambda=325 \mathrm{~nm})$ and a $75-\mathrm{cm}$ monochromator (GaAs photomultiplier tube). The electrical properties of the PFO/YZO-NR PDs were examined by using a semiconductor device parameter analyzer of Keysight B1500A (Keysight Technologies, 
Santa Rosa, CA, USA). The UV photoresponse properties of the devices were assessed under UV illumination $(\lambda=365 \mathrm{~nm})$ with the optical power density $\left(\mathrm{P}_{\mathrm{opt}}\right)$ of $0-0.6 \mathrm{~mW} / \mathrm{cm}^{2}$.

\section{Results and Discussion}

Since both graphene and zinc oxide have a hexagonal lattice configuration along the $a$-plane $[54,55]$, the YZO-NRs were effectively grown on graphene even though no seed layer was used for the hydrothermal synthesis process (see the inset of Figure 2a). However, each nanorod has an irregular direction, presumably, because of the difference in $a$-axis lattice constants between zinc oxide $(\cong 3.25 \AA)$ and graphene $(\cong 2.46 \AA)[54,55]$. Despite such an arbitrary direction of YZO-NRs, most of the nanorods possess a high aspect ratio (i.e., $l_{\text {ave }} \sim 40 \mathrm{~nm}$ and $d_{\text {ave }} \sim 250 \mathrm{~nm}$ ) that may give rise to the increase in the photon collection area (i.e., large surface-to-volume ratio) for the PFO/YZO-NR PD.
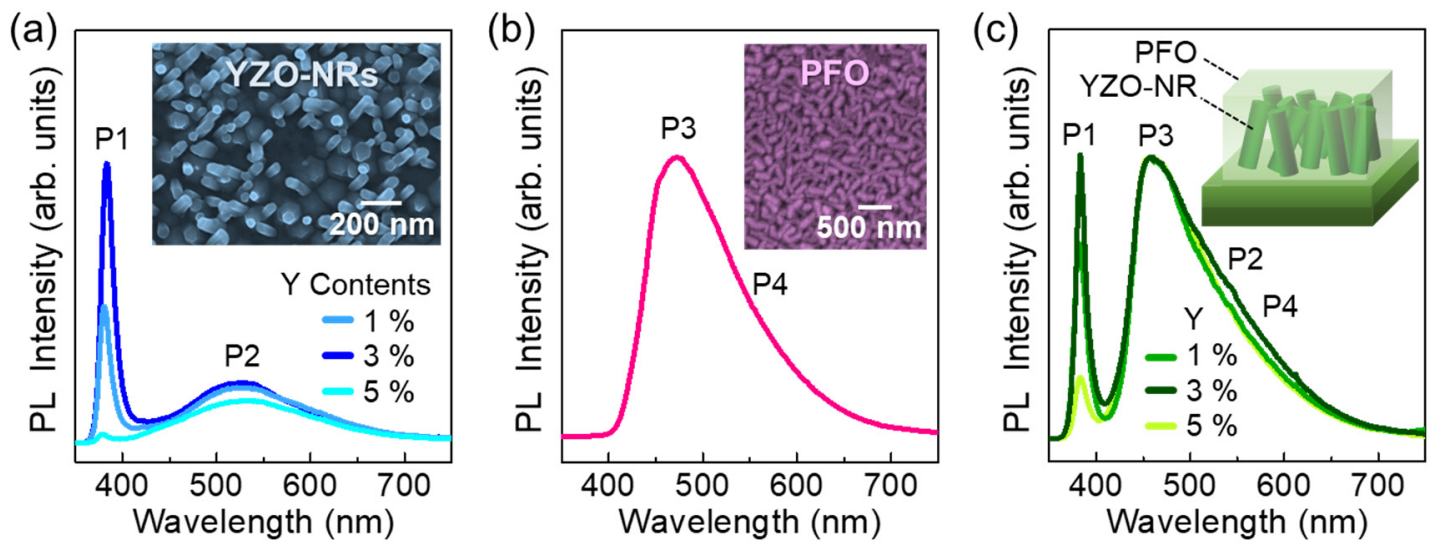

Figure 2. Optical properties of the prepared materials: (a) PL spectra of YZO-NRs with the different $Y$ contents $(1 \%-5 \%)$, (b) PL spectrum of PFO, and (c) PL spectra for the hybrid heterostructures of the PFO/YZO-NR (Y: $1 \%-5 \%)$. The inset of $(\mathbf{a})$ and $(\mathbf{b})$ display the SEM images of YZO-NRs and PFO, respectively; and the inset of (c) illustrates the PFO/YZO-NR heterostructure.

Figure 2a shows the optical properties of the YZO-NRs (Y: 1-5\%). Regardless of the Y contents, all samples exhibit two predominant PL features at P1 $380 \mathrm{~nm}$ and P2 $~ 530 \mathrm{~nm}$. UV emission (i.e., P1) originates from the near band-edge radiative optical transition, and green emission (i.e., P2) arises from the deep-level transition, associating with oxygen-related defects (e.g., oxygen vacancies $\left(V_{O}\right)$ ) in host material $\mathrm{ZnO}$ [21-23]. Compared to the YZO-NRs with $\mathrm{Y}=1 \%$, the sample with $\mathrm{Y}=3 \%$ displays much stronger UV emission whereas deep level emission is almost comparable. This infers that the crystal quality of $\mathrm{YZO}$ was dramatically improved via use of an appropriate concentration of $\mathrm{Y}$ because the $\mathrm{Y}$ dopants act as the $V_{O}$ compensators $[20,23]$. However, $U V$ emission became significantly weak when the $\mathrm{Y}$ concentration was increased up to $5 \%$. We impute such a degradation to the lattice distortion in YZO because the incorporation of the abundant $Y$ dopants may not only create the $Y-Y$ and/or $Y-O$ clusters [56] but also cause the residual stress in the $Y Z O$ crystal due to the larger ionic radius of $\mathrm{Y}^{3+}$ (0.92 $\AA$ ) than that of $\mathrm{Zn}^{2+}(0.74 \AA)$ [20].

The morphological and the optical properties of PFO are shown in Figure 2b. To investigate the intrinsic properties of $\mathrm{PFO}$, we prepared the reference sample of the pristine PFO layer by coating it onto the $\mathrm{SiO}_{2} / \mathrm{Si}$ substrate. The PFO layer displays a grain-aggregated topography (see the inset of Figure $2 b$ ), resulting from the volume shrinkage during the thermal treatment [41]. For the PL characteristics, the PFO layer clearly reveals a huge blue-emission peak (P3) at $\sim 470 \mathrm{~nm}$ with a broad hump (P4) at $\sim 540 \mathrm{~nm}$ (Figure 2b). These correspond to the typical PL feature of $\beta$-phase PFO [41,43] that comprises a flatter geometry of backbone-like PFO molecules. Namely, the PFO layer was well-dispersed along the surface direction. This will increase the active contact area of PFO to YZO-NRs; and it may allow an effective formation of the stable heterojunction between $\mathrm{p}-\mathrm{PFO}$ and $\mathrm{n}-\mathrm{YZO}$. Furthermore, the higher carrier mobility of $\beta$-phase PFO than that of glassy PFO [44] may also improve the photoresponse 
characteristics of the PFO/YZO-NR PD device. Figure 2c shows the PL spectra of the PFO/YZO-NRs hybrid heterostructures. The samples reveal no additional peaks, except for intrinsic PL properties from both YZO-NRs (i.e., P1 and P2) and PFO (i.e., P3 and P4). Although the samples exhibit a similar aspect in their PL spectra; as discussed above, the intensity ratio of P1 (i.e., UV) to P3 (i.e., green) is maximized in the sample doped with an appropriate fraction of $\mathrm{Y}$ (i.e., $3 \%$ ).

Next, we characterized the electrical characteristics of the PFO/YZO-NR PDs. To investigate the effect of the $Y$ contents on the current-voltage $(\mathrm{I}-\mathrm{V})$ characteristics, we fabricated three different PFO/YZO-NR PD samples by using three different types of YZO-NRs (i.e., Y: 1\%, 3\%, and 5\%). For convenience, we refer to those samples as $\mathrm{Y} 1, \mathrm{Y} 3$, and $\mathrm{Y} 5$, respectively. Under the dark state, as shown in Figure $3 a$, all of the samples clearly show the rectifying behavior with the turn-on voltage of $\sim 0.75 \mathrm{~V}$ and the ideality factor of $\sim 3.1$. Such a large ideality factor might be attributed to the multiple current pathways, arising from the surface states created by native point defects on the YZO-NR surface [57]. When illuminating the 365-nm UV light $\left(P_{\text {opt }}=0.2 \mathrm{~mW} / \mathrm{cm}^{2}\right)$ onto the devices, the current level is considerably increased in both the positive and the negative bias regions. Particularly, the Y3 sample exhibits a higher photo-to-dark current ratio than Y1 and Y5 (Figure 3b). This signifies that an appropriate concentration of $Y$ (i.e., 3\%) can help increasing the photocarrier density, as discussed below.
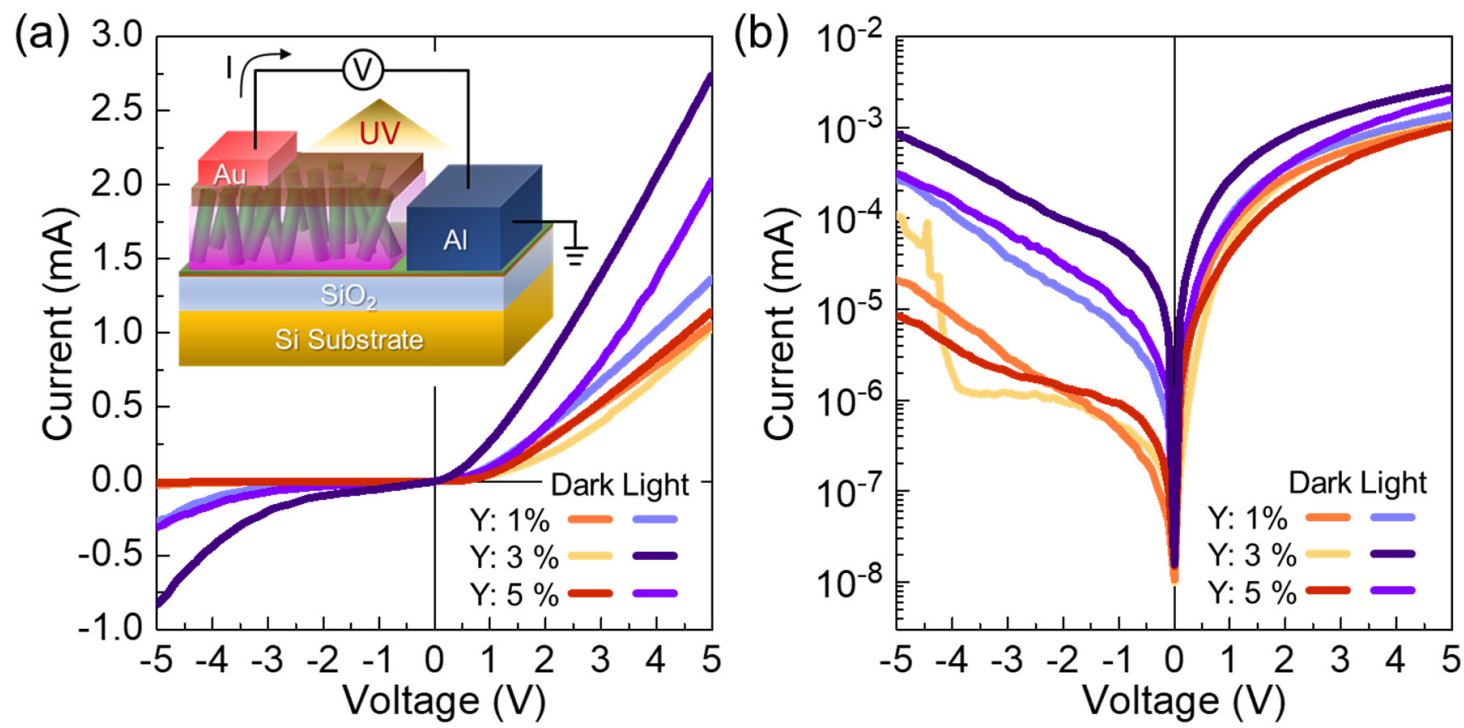

Figure 3. I-V characteristic curves of the PFO/YZO-NR PDs (Y: 15\%) under dark and UV illumination $\left(\mathrm{P}_{\mathrm{opt}}=0.2 \mathrm{~mW} / \mathrm{cm}^{2}\right)$ : (a) linear scale and $(\mathbf{b})$ semi-logarithmic scale.

To explain such a hypothesis, we interpret the effect of the $Y$ contents on the photocurrent of the PFO/YZO-NR PD. Figure 4 schematically represents the nanorod surfaces and their corresponding energy band diagrams for two different types of YZO-NRs; i.e., one contains a lower concentration of Y (Figure $4 a, b)$, and the other has a moderate concentration of $Y$ (Figure $4 c, d)$. As aforementioned, the $\mathrm{Y}$ dopants play a key role as the $\mathrm{V}_{\mathrm{O}}$ compensators $[20,23]$. Therefore, the former one might have a high concentration of negative charge carriers because a lower $Y$ concentration would leave a large number of $\mathrm{V}_{\mathrm{O}}$ at the nanorod surface. In this case, a lot of oxygen molecules would be adsorbed at the abundant $\mathrm{V}_{\mathrm{O}}$ sites; hence, the large number of negatively charged oxygen ions could be created via bonding of $\mathrm{O}_{2}$ molecules with negative charge carriers at $\mathrm{V}_{\mathrm{O}}$ sites (i.e., $\mathrm{O}_{2}+\mathrm{e}^{-}=\mathrm{O}_{2}{ }^{-}$). As a result, the YZO-NR will have a plenty of negatively charged oxygen trap sites at its surface (Figure $4 \mathrm{a}$ ).

When the UV light is illuminated onto the YZO-NR, electron-hole pairs (EHPs) are generated inside the nanorod (Figure $4 \mathrm{~b}$ ). Then, the large concentration of photo-generated holes would be trapped at negatively ionized oxygen molecules, whereas the photo-electrons could contribute to the photocurrent (i.e., $2 \mathrm{O}_{2}^{-}+2 \mathrm{EHP} \rightarrow 2 \mathrm{O}_{2}^{-}+2 \mathrm{~h}^{+}+2 \mathrm{e}^{-} \rightarrow 2 \mathrm{O}_{2}+2 \mathrm{e}^{-}$). Consequently, such a trapping behavior will 
result in the deficiency of photo holes in the whole device system; thus, the photocurrent may seldom increase even under light illumination. However, the latter one (i.e., moderate $Y$ concentration) contains a small concentration of negatively ionized oxygen molecules because of rare $\mathrm{V}_{\mathrm{O}}$ (Figure $4 \mathrm{c}$ ). In this case, only the small portion of photo holes would recombine with negatively ionized oxygen molecules; then, the rest of photo holes would remain free $\left(\mathrm{O}_{2}^{-}+2 \mathrm{EHP} \rightarrow \mathrm{O}_{2}^{-}+2 \mathrm{~h}^{+}+2 \mathrm{e}^{-} \rightarrow \mathrm{O}_{2}+2 \mathrm{e}^{-}+\mathrm{h}^{+}\right)$ (Figure $4 \mathrm{~d}$ ). Those residual photo holes can also contribute to the carrier transport as free holes. Eventually, the photocurrent will therefore considerably increase under light illumination.

(a)

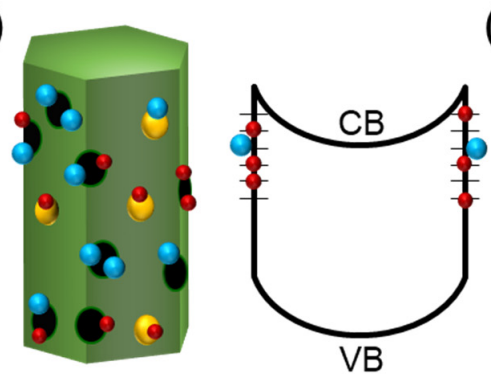

$\mathrm{O}_{2}+\mathrm{e}^{-} \rightarrow \mathrm{O}_{2}^{-}$

(Abundant $\mathrm{V}_{\mathrm{O}}$, Abundant $\mathrm{O}_{2}^{-}$)

(c)

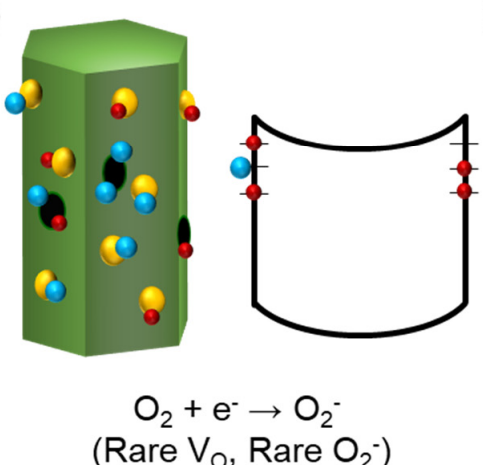

(b)

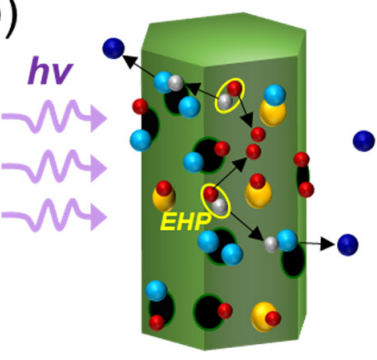

$2 \mathrm{O}$

$2 \mathrm{EHP} \rightarrow 2 \mathrm{O}_{2}^{-}+2 \mathrm{~h}^{+}+2 \mathrm{e}^{-} \rightarrow 2 \mathrm{O}_{2}+2 \mathrm{e}^{-}$

(Deficient $\mathrm{h}^{+}$due to Compensation with $\mathrm{O}_{2}^{-}$)

(d)

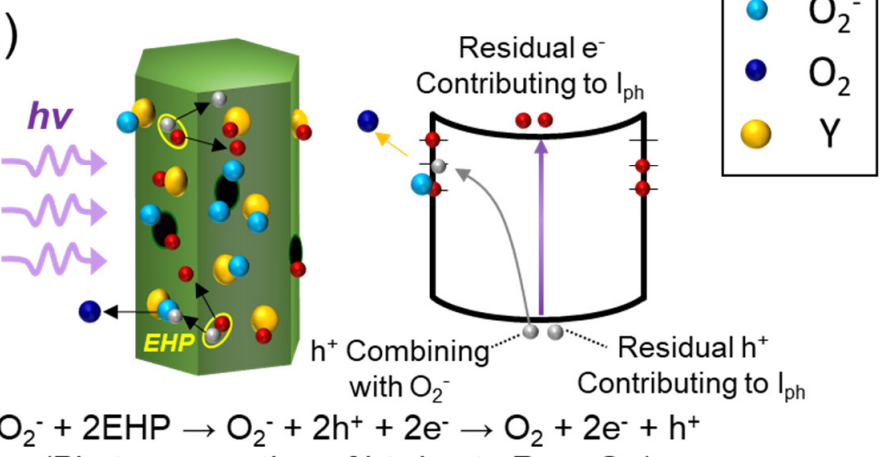

(Photo-generation of $\mathrm{h}^{+}$due to Rare $\mathrm{O}_{2}^{-}$)

Figure 4. Schematic illustrations of the YZO-NR surface (left-hand-side) and its corresponding energy band diagram (right-hand-side): Defective YZO-NR with a lower $Y$ concentration at (a) dark and (b) UV illumination, and less-defective YZO-NR with a moderate $Y$ concentration at (c) dark and

(d) UV illumination. The chemical formula in each figure denotes the chemical reaction under the given situation.

Based upon all the above, we chose the Y3 sample for further characterizations. Figure 5 displays the I-V characteristic curves of $Y 3$ under UV illumination with various $P_{\text {opt }}\left(0.1-0.6 \mathrm{~mW} / \mathrm{cm}^{2}\right)$. Here, we note that the UV-A $(\lambda=365 \mathrm{~nm})$ was used in this experiment because we previously observed that the short penetration depth of the shorter wavelength-UV-light (e.g., UV-B and UV-C) led to the weak photoresponse characteristics in $\mathrm{ZnO}$ [58]. As $\mathrm{P}_{\text {opt }}$ increases from 0.1 to $0.6 \mathrm{~mW} / \mathrm{cm}^{2}$, the current level gradually increases in both $\pm \mathrm{V}$ regions (Figure 5a). The increased photocurrent can be ascribed to the excellent UV adsorption characteristics of both PFO and YZO-NR (see Supplementary Materials, Figure S1). Particularly, the device exhibits a drastic increase in its photocurrent at the reverse bias region (Figure $5 \mathrm{~b}$ ). When $\mathrm{P}_{\mathrm{opt}}=0.6 \mathrm{~mW} / \mathrm{cm}^{2}$ and $\mathrm{V}=-3.5 \mathrm{~V}$, the current was increased up to $\sim 1.3 \mathrm{~mA}$ from the dark current of $\sim 1 \mu \mathrm{A}$. This is an indicative of the high photo-to-dark current ratio $\left(>10^{3}\right)$ of the $\mathrm{Y} 3$ device. To assess the $\mathrm{P}_{\text {opt }}$ dependence of the steady-state photocurrent (i.e., $\mathrm{I}_{\mathrm{ph}}=\mathrm{I}_{\text {light }}-\mathrm{I}_{\text {dark }}$ ) and its corresponding steady-state on/off ratio (i.e., $\mathrm{I}_{\mathrm{ph}} / \mathrm{I}_{\text {dark }}$ ), we extracted the $\mathrm{I}_{\mathrm{ph}}$ and $\mathrm{I}_{\mathrm{ph}} / \mathrm{I}_{\text {dark }}$ values from the $\mathrm{P}_{\text {opt }}$-dependent $\mathrm{I}-\mathrm{V}$ curves, and plotted those as a function of $\mathrm{P}_{\text {opt }}$ (Figure 6). At the forward bias states, $\mathrm{I}_{\mathrm{ph}}$ and $\mathrm{I}_{\mathrm{ph}} / \mathrm{I}_{\text {dark }}$ monotonically increases with increasing $\mathrm{P}_{\text {opt }}$ (Figure 6a,b). However, at the reverse bias states, both $\mathrm{I}_{\mathrm{ph}}$ and $\mathrm{I}_{\mathrm{ph}} / \mathrm{I}_{\text {dark }}$ exponentially increase with increasing $\mathrm{P}_{\mathrm{opt}}$ because of the 
clear rectification characteristics in the PFO/YZO-NR heterojunction diode (Figure 6c,d). Accordingly, the high magnitude of $\mathrm{I}_{\mathrm{ph}} / \mathrm{I}_{\text {dark }}\left(>10^{3}\right)$ is achievable at $\mathrm{V}=-3.5 \mathrm{~V}$.
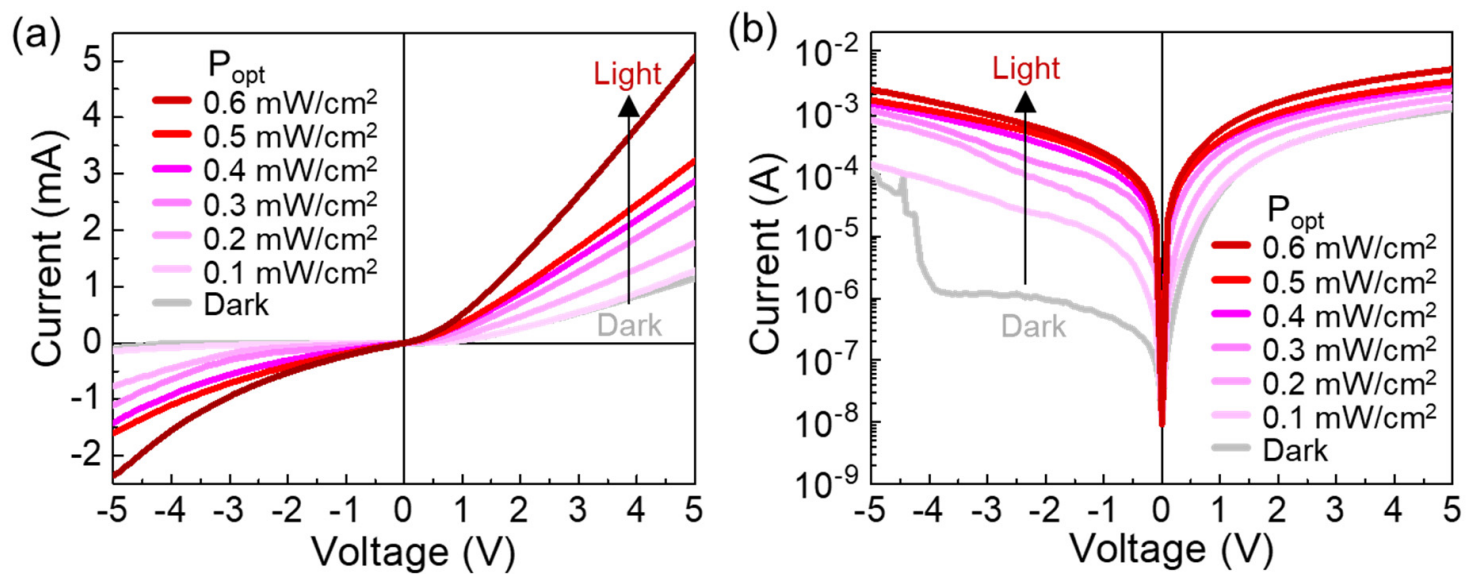

Figure 5. I-V characteristics of the $\mathrm{Y} 3$ device under UV illumination with various $\mathrm{P}_{\text {opt }}$ : (a) linear scale and (b) semi-logarithmic scale.
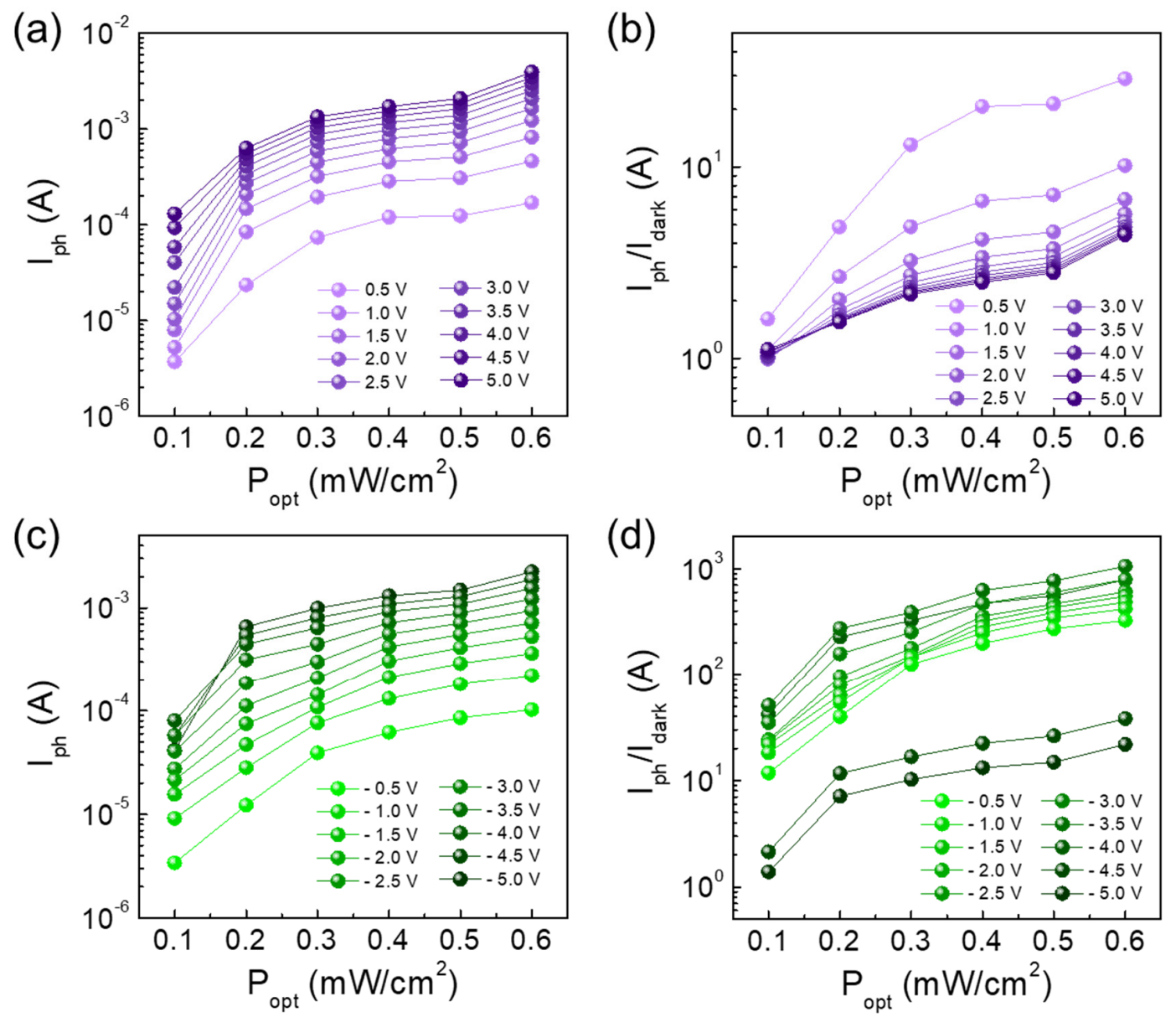

Figure 6. Photoresponse characteristics at various bias voltages of the $Y 3$ device: (a) $I_{p h}$ and $(\mathbf{b}) I_{p h} / I_{\text {dark }}$ as a function of $\mathrm{P}_{\mathrm{opt}}$ at forward bias states; and (c) $\mathrm{I}_{\mathrm{ph}}$ and (d) $\mathrm{I}_{\mathrm{ph}} / \mathrm{I}_{\mathrm{dark}}$ at reverse bias states.

Next, we examined the photoresponse transient characteristics of the $\mathrm{Y} 3$ device at a UV light switching frequency of $0.5 \mathrm{~Hz}\left(\mathrm{P}_{\mathrm{opt}}=0.6 \mathrm{~mW} / \mathrm{cm}^{2}\right)$. As shown in Figure 7 , the device reveals the typical $\mathrm{I}_{\mathrm{ph}}$ transient waveforms under both the forward and reverse bias states. However, the on-state current is more stable at reverse bias (Figure 7a) than that at forward bias (Figure 7b). Accordingly, 
the rising time $\left(\tau_{\mathrm{r}}=0.13 \mathrm{~s}\right)$ at reverse bias is faster than that at forward $\left(\tau_{\mathrm{r}}=0.51 \mathrm{~s}\right)$. Similarly, the decay time $\left(\tau_{\mathrm{d}}=0.22 \mathrm{~s}\right)$ is also shorter at the reverse bias state, compared to that at the forward bias state $\left(\tau_{d}=0.44 \mathrm{~s}\right)$. Such a bias dependence of the photoresponse time is thought as associating with the difference in carrier transport mechanisms under forward and reverse bias conditions, as explained below.

(a)
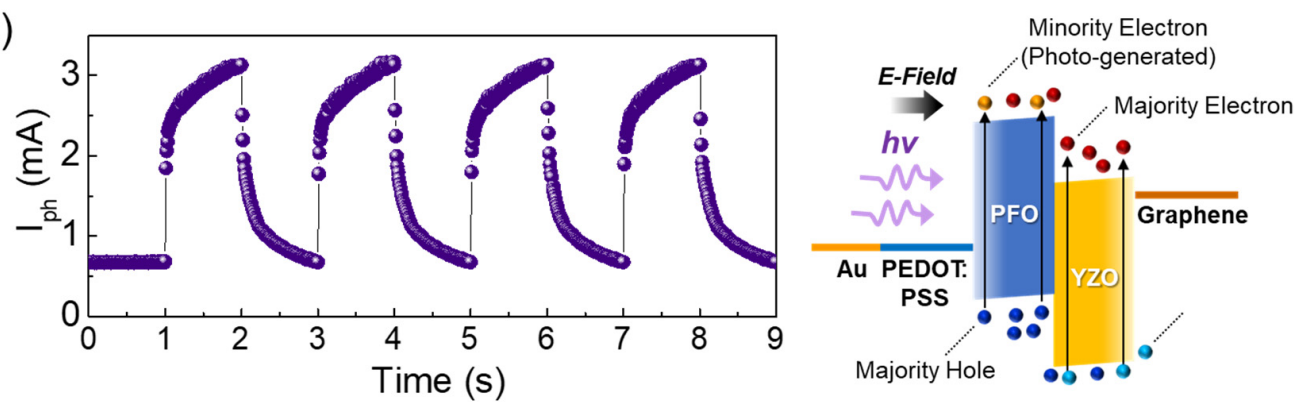

(b)
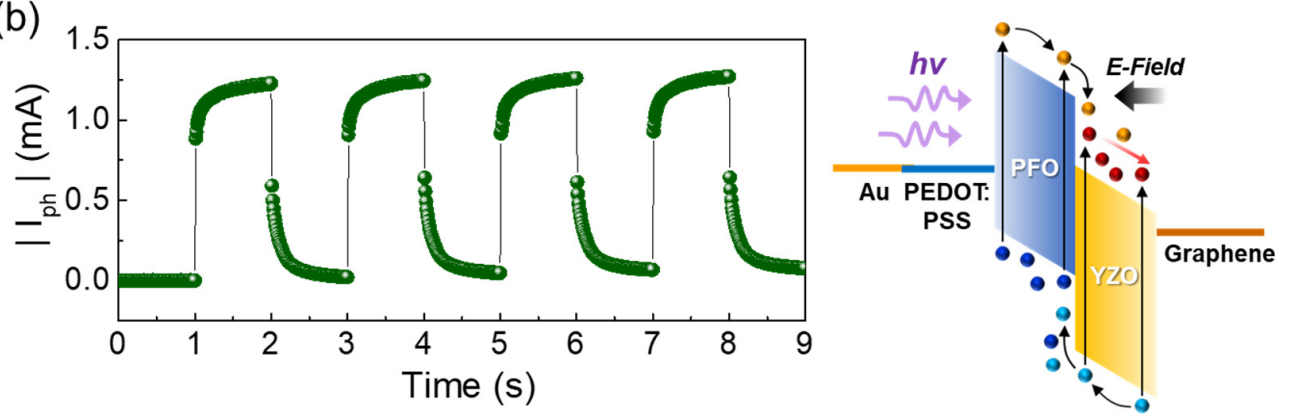

Figure 7. Photoresponse transient waveforms of the $\mathrm{Y} 3$ device under UV illumination $\left(\mathrm{P}_{\mathrm{opt}}=0.6 \mathrm{~mW} / \mathrm{cm}^{2}\right)$ : (a) under forward bias at $+3.5 \mathrm{~V}$ and $(\mathbf{b})$ under reverse bias at $-3.5 \mathrm{~V}$. The right-hand-side insets of (a) and (b) represent the energy band diagrams and their corresponding photocarrier transport behaviors at forward and reverse bias states, respectively.

At thermal equilibrium, a large internal electric-field would be created along the direction from YZO-NR to PFO because the work function energy of PFO is greater than that of YZO-NR (see Supplementary Materials, Figure S2). Under the forward bias condition, therefore, the large portion of the applied voltage should be spent to release the large internal electric-field. In this case, the residual potential barrier at the PFO/YZO-NR interface would impede the drift of photocarriers while a diffusion process could easily take place at the PFO/YZO-NR heterojunction (Figure 7a, inset). At the initial stage of light illumination, the injection barriers at the conduction band and the valence band would cause the accumulation of photo-generated electrons and holes at YZO-NR and PFO, respectively. If one keeps on illuminating the UV light, more of photocarriers will be accumulated at the PFO/YZO-NR hetero-interface; then, the accumulated electrons and holes would jump over the injection barriers so as to diffuse into PFO and YZO-NR, respectively. On the other hand, the reverse bias voltage would give rise to the increase in the electric field across the heterojunction, leading to the drift conduction of photocarriers (Figure 7b, inset). According to Ramo's theorem [59], the photoresponse time relies on the photocarrier velocity; hence, the fast photoresponse could be achievable when the carrier transport is mostly governed by the drift carrier action. Therefore, it can be inferred the faster photoresponse at reverse bias in our $\mathrm{Y} 3$ device to arise from the drift conduction of photocarriers.

Finally, we calculated some key parameters of the Y3 device. For PDs, the quantum efficiency $\left(\eta_{Q E}\right)$ is one of the most important figure-of-merits, indicative of an ability to convert the incident photons to the electronic carriers. The $\eta_{Q E}$ value can be easily determined in terms of $\mathrm{I}_{\mathrm{ph}}$ and $\mathrm{P}_{\mathrm{opt}}[60]$ by using the following equation:

$$
\eta_{Q E}=\frac{\mathrm{I}_{\mathrm{ph}}}{\mathrm{P}_{\mathrm{opt}}} \times \frac{h v}{q}(\times 100 \%)
$$


where $h v$ is the photon energy of the incident light, and $q$ is the elementary unit charge. Using Equation (1), we obtained a high magnitude of $\eta_{Q E} \sim 690 \%$ at $-3.5 \mathrm{~V}$ under UV illumination with $\mathrm{P}_{\mathrm{opt}}$ of $0.6 \mathrm{~mW} / \mathrm{cm}^{2}$. We ascribe such a high value of $\eta_{Q E}$ to the decreased photocarrier trap-sites because, as discussed earlier, the incorporation of $Y$ dopants may effectively compensate the oxygen-related surface defects in YZO NRs. According to the literatures [61,62], $\eta_{Q E}$ is directly relevant to both responsivity $(R)$ and detectivity $\left(D^{*}\right)$ as follows:

$$
\begin{gathered}
R=\eta_{Q E} \frac{q}{h v} \\
D^{*}=\frac{R}{\sqrt{2 q J_{d a r k}}}
\end{gathered}
$$

where $J_{\text {dark }}$ is the current density at dark space. Due to the low value of $J_{\text {dark }}\left(=1.06 \times 10^{-6} \mathrm{~A} / \mathrm{cm}^{2}\right)$ and the large magnitude of $\eta_{Q E}$ for our Y3 device, $D^{*}$ was computed to be $3.34 \times 10^{12} \mathrm{~cm} \cdot \mathrm{Hz}^{1 / 2} \cdot \mathrm{W}^{-1}$ by using Equations (2) and (3). This value is greater than others [50,51], except for that of the PFO/ZnO PD consisting of the avalanche type of multiple PFO/ZnO stacks [52] (See Table 1). In addition, the high magnitude of $\eta_{Q E}$ is also closely related to the photocarrier lifetime $\left(\tau_{\mathrm{PC}}\right)$ and the photocarrier diffusion length $\left(L_{\mathrm{PC}}\right)$ as follows $[60,63]$ :

$$
\begin{gathered}
\tau_{\mathrm{PC}} \simeq \eta_{\mathrm{QE}} \cdot \tau_{\mathrm{TR}} \\
L_{\mathrm{PC}}=\sqrt{D_{\mathrm{PC}} \cdot \tau_{\mathrm{PC}}}
\end{gathered}
$$

where $\tau_{\mathrm{TR}}$ and $D_{\mathrm{PC}}$ are the transit time and the diffusion coefficient of the photocarrier. Using the average values of photocurrent and time delay during four pulses in Figure $7 \mathrm{~b}, \eta_{Q E(\text { (ave) }}$ and $\tau_{\mathrm{TR}(\mathrm{ave})}$ were calculated to be $660 \%$ and $0.17 \mathrm{~s}$, respectively. Therefore, we could estimate $\tau_{\mathrm{PC}}$ of $\mathrm{Y} 3$ at reverse bias to be $\sim 1.16 \mathrm{~s}$. Since the larger value of $\tau_{\mathrm{PC}}$ is responsible for the longer length of $L_{\mathrm{PC}}$, one can expect our $Y 3$ device to possess a long $L_{\mathrm{PC}}$. We accredit the large magnitude of $L_{\mathrm{PC}}$ to the conformation of the $\beta$-phase PFO molecules. As mentioned earlier, $\beta$-phase backbone-like PFO has a flatter geometry of closely-fitted polymer chains. Since $\beta$-phase PFO has a higher carrier mobility than that of glassy PFO [44], the migration of photocarriers can effectively occur in the organic-inorganic hybrid heterojunction. Consequently, we can conclude that the excellent UV photoresponse characteristics arise from the synergetic effects from both the incorporation of $Y$ (i.e., compensation of surface defects)

\begin{tabular}{|c|c|c|c|c|c|c|c|c|c|c|}
\hline $\begin{array}{l}\text { Materials and } \\
\text { Structures }\end{array}$ & $\begin{array}{l}\lambda_{U V} \\
(\mathrm{~nm})\end{array}$ & $\begin{array}{c}P_{\text {opt }} \\
\left(\mathrm{mW} / \mathrm{cm}^{2}\right)\end{array}$ & $\begin{array}{l}V_{B} \\
(V)\end{array}$ & $\begin{array}{l}\tau_{r} \\
(s)\end{array}$ & $\begin{array}{l}\tau_{\mathrm{d}} \\
(\mathrm{s})\end{array}$ & $\begin{array}{l}\eta_{Q E} \\
(\%)\end{array}$ & $\mathbf{I}_{\mathrm{ph}} / \mathrm{I}_{\mathrm{dark}}$ & $\underset{(\mathrm{A} / \mathrm{W})}{\mathrm{R}}$ & $\frac{\mathrm{D}}{\left(\mathrm{cm} \cdot \mathrm{Hz}^{1 / 2} \cdot \mathrm{W}^{-1}\right)}$ & Ref. \\
\hline ZnO NRs/PFO & 365 & 0.6 & -3.5 & 0.13 & 0.22 & 690 & $>10^{3}$ & 2.03 & $3.34 \times 10^{12}$ & $\begin{array}{l}\text { This } \\
\text { work }\end{array}$ \\
\hline ZnO NRs/PFO & 300 & & -1 & & & 70 & $\sim 10^{2}$ & 0.18 & $\sim 1 \times 10^{12}$ & [50] \\
\hline $\mathrm{ZnO}$ TF/PFO & & 0.01 & 2 & & & & $\sim 10^{1}$ & 0.2 & $>3 \times 10^{10}$ & [51] \\
\hline $\mathrm{ZnO} N \mathrm{NP} / \mathrm{PFO}$ & 350 & 1 & -10 & & $43 \mathrm{~m}$ & 2816 & $>10^{3}$ & 4.17 & $4.93 \times 10^{12}$ & [52] \\
\hline
\end{tabular}
and the formation of $\beta$-phase PFO (i.e., increase of carrier conductivity).

Table 1. Comparison of the photoresponse characteristics for various $\mathrm{PFO} / \mathrm{ZnO}$-based organic-inorganic hybrid heterojunction PDs.

Note: NRs, Nanorods; TF, Thin film; NP, Nanoparticle; $\lambda_{U V}$, Wavelength of UV light; $V_{B}$, Bias voltage.

\section{Summary and Conclusions}

We fabricated the high-performance PFO/YZO-NR organic-inorganic hybrid heterojunction PD that shows the outstanding UV photoresponse characteristics. The device recorded a high magnitude of $\eta_{Q E}$ to be $\sim 690 \%$ even under low-power UV illumination $\left(\mathrm{P}_{\mathrm{opt}}=0.6 \mathrm{~mW} / \mathrm{cm}^{2}\right)$. Accordingly, a high $\mathrm{I}_{\mathrm{ph}} / \mathrm{I}_{\text {dark }}$ ratio $\sim 10^{3}$ and the large $D^{*}$ value $\sim 3.34 \times 10^{12} \mathrm{~cm} \cdot \mathrm{Hz}^{1 / 2} \cdot \mathrm{W}^{-1}$ were accomplished the reverse bias voltage of $-3.5 \mathrm{~V}$. In addition, the device revealed stable and fast $\mathrm{UV}$ photoresponse characteristics 
in its photocurrent transient waveforms (i.e., $\tau_{\mathrm{r}}=0.13 \mathrm{~s}$ and $\tau_{\mathrm{d}}=0.22 \mathrm{~s}$ ). We interpreted these excellent photoresponse characteristics as resulting from both the increased carrier mobility via forming $\beta$-phase PFO and the decreased VO via Y-doping into YZO-NRs. The results pronounce that the $\beta$-phase $\mathrm{p}-\mathrm{PFO} / \mathrm{n}-\mathrm{YZO}-\mathrm{NR}$ organic-inorganic hybrid heterostructure could be a good choice for demonstrating a high-performance UV PD.

Supplementary Materials: The following are available online at http://www.mdpi.com/2079-4991/10/8/1486/s1, Figure S1: Optical absorption spectra of PFO, YZO-NRs, and PFO/YZO-NRs; Figure S2: Energy band diagrams of the PFO/YZO-NR heterojunction: (a) before contact, (b) at thermal equilibrium, (c) under forward bias, and $(\mathrm{d})$ under reverse bias. $\mathrm{E}_{\mathrm{F}}, \mathrm{E}_{\mathrm{c}}$, and $\mathrm{E}_{\mathrm{v}}$ in (a) denote the Fermi level, conduction band, and valence band, respectively.

Author Contributions: Investigation and writing—original draft, Y.L.; methodology and formal analysis, S.Y.K.; conceptualization and funding acquisition, D.Y.K.; supervision and writing-review and editing, S.L. All authors have read and agreed to the published version of the manuscript.

Funding: This research was supported by the National Research Foundation of Korea through Basic Science Research Programs (2016R1A6A1A03012877, 2018R1D1A1B07051011, 2019R1A2C1085448) funded by the Korean government.

Conflicts of Interest: The authors declare no conflicts of interest.

\section{References}

1. Li, G.; Suja, M.; Chen, M.; Bekyarova, E.; Haddon, R.C.; Liu, J.; Itkis, M.E. Visible-Blind UV Photodetector Based on Single-Walled Carbon Nanotube Thin Film/ZnO Vertical Heterostructures. ACS Appl. Mater. Interfaces 2017, 9, 37094-37104. [CrossRef] [PubMed]

2. Lee, D.; Seol, M.-L.; Motilal, G.; Kim, B.; Moon, D.-I.; Han, J.-W.; Meyyappan, M. All 3D-Printed Flexible $\mathrm{ZnO}$ UV Photodetector on an Ultraflat Substrate. ACS Sensors 2020, 5, 1028-1032. [CrossRef] [PubMed]

3. Zou, Y.; Zhang, Y.; Hu, Y.; Gu, H. Ultraviolet Detectors Based on Wide Bandgap Semiconductor Nanowire: A Review. Sensors 2018, 18, 2072. [CrossRef] [PubMed]

4. Chen, M.; Zhao, B.; Hu, G.; Fang, X.; Wang, H.; Wang, L.; Luo, J.; Han, X.; Wang, X.; Pan, C.; et al. Piezo-Phototronic Effect Modulated Deep UV Photodetector Based on ZnO-Ga2O3 Heterojuction Microwire. Adv. Funct. Mater. 2018, 28, 1706379. [CrossRef]

5. Kang, J.-W.; Kim, B.-H.; Song, H.; Jo, Y.-R.; Hong, S.-H.; Jung, G.Y.; Kim, B.-J.; Park, S.-J.; Cho, C.-H. Radial Multi-Quantum Well ZnO Nanorod Arrays for Nanoscale Ultraviolet Light-Emitting Diodes. Nanoscale 2018, 10, 14812-14818. [CrossRef]

6. Deng, G.; Zhang, Y.; Yu, Y.; Han, X.; Wang, Y.; Shi, Z.; Dong, X.; Zhang, B.; Du, G.; Liu, Y. High-Performance Ultraviolet Light-Emitting Diodes Using n-ZnO/p-hBN/p-GaN Contact Heterojunctions. ACS Appl. Mater. Interfaces 2020, 12, 6788-6792. [CrossRef]

7. Dhar, S.; Majumder, T.; Mondal, S.P. Graphene Quantum Dot-Sensitized ZnO Nanorod/Polymer Schottky Junction UV Detector with Superior External Quantum Efficiency, Detectivity, and Responsivity. ACS Appl. Mater. Interfaces 2016, 8, 31822-31831. [CrossRef]

8. Hsu, C.-L.; Lin, Y.-H.; Wang, L.-K.; Hsueh, T.-J.; Chang, S.-P.; Chang, S.-J. Tunable UV- and Visible-Light Photoresponse Based on p-ZnO Nanostructures/n-ZnO/Glass Peppered with Au Nanoparticles. ACS Appl. Mater. Interfaces 2017, 9, 14935-14944. [CrossRef]

9. Chang, Y.-C. Low Temperature and Large-scale Growth of ZnO Nanoneedle Arrays with Enhanced Optical and Surface-enhanced Raman Scattering Properties. Sens. Actuator B-Chem. 2016, 225, 498-503. [CrossRef]

10. Li, J.-M. $4 \mathrm{~nm} \mathrm{ZnO} \mathrm{Nanocrystals} \mathrm{Fabrication} \mathrm{Through} \mathrm{Electron} \mathrm{Beam} \mathrm{Irradiation} \mathrm{on} \mathrm{the} \mathrm{Surface} \mathrm{of} \mathrm{a} \mathrm{ZnO}$ Nanoneedle Formed by Thermal Annealing. CrystEngComm 2017, 19, 32-39. [CrossRef]

11. Chang, Y.-M.; Lin, M.-L.; Lai, T.-Y.; Chen, C.-H.; Lee, H.-Y.; Lin, C.-M.; Wu, Y.-C.S.; Lin, Y.-F.; Juang, J.-Y. Broadband Omnidirectional Light Trapping in Gold-Decorated ZnO Nanopillar Arrays. ACS Appl. Mater. Interfaces 2017, 9, 11985-11992. [CrossRef] [PubMed]

12. Li, X.; Cheng, S.; Deng, S.; Wei, X.; Zhu, J.; Chen, Q. Direct Observation of the Layer-by-Layer Growth of ZnO Nanopillar by in situ High Resolution Transmission Electron Microscopy. Sci. Rep. 2017, 7, 40911. [CrossRef] [PubMed] 
13. Mishra, Y.K.; Adelung, R. ZnO Tetrapod Materials for Functional Applications. Mater. Today 2018, 21, 631-651. [CrossRef]

14. Faraji, N.; Ulrich, C.; Wolff, N.; Kienle, L.; Adelung, R.; Mishra, Y.K.; Seidel, J. Visible-Light Driven Nanoscale Photoconductivity of Grain Boundaries in Self-Supported ZnO Nano- and Microstructured Platelets. Adv. Electron. Mater. 2016, 2, 1600138. [CrossRef]

15. Lee, Y.; Lee, D.J.; Cho, H.D.; Yoon, I.T.; Shon, Y.; Lee, S. Thermodynamic Behaviors of Excitonic Emission in ZnO Nanorods Grown by Pulsed Laser Deposition. J. Lumin. 2017, 190, 314-318. [CrossRef]

16. Lee, S.; Lee, Y.; Kim, D.Y.; Panin, G.N. Highly Efficient Low-Voltage Cathodoluminescence of Semiconductive Nanoporous ZnMnO Green Phosphor Films. Appl. Surf. Sci. 2019, 470, 234-240. [CrossRef]

17. Lee, S.; Lee, Y.; Panin, G.N. Novel Green Luminescent and Phosphorescent Material: Semiconductive Nanoporous ZnMnO with Photon Confinement. ACS Appl. Mater. Interfaces 2017, 9, 20630-20636. [CrossRef]

18. Lee, S.; Lee, Y.; Kim, D.Y.; Panin, G.N. Multicolor Emission from Poly(p-Phenylene)/Nanoporous ZnMnO Organic-Inorganic Hybrid Light-Emitting Diode. ACS Appl. Mater. Interfaces 2016, 8, 35435-35439. [CrossRef]

19. Kaur, N.; Lee, Y.; Kim, D.Y.; Lee, S. Optical bandgap tuning in nanocrystalline ZnO:Y films via forming defect-induced localized bands. Mater. Des. 2018, 148, 30-38. [CrossRef]

20. Heo, S.; Sharma, S.K.; Lee, S.; Lee, Y.; Kim, C.; Lee, B.; Lee, H.; Kim, D.Y. Effects of Y Contents on Surface, Structural, Optical, and Electrical Properties for Y-Doped ZnO Thin Films. Thin Solid Films 2014, 558, 27-30. [CrossRef]

21. Sharma, S.K.; Kaur, N.; Lee, B.; Kim, C.; Lee, S.; Kim, D.Y. Diameter and density controlled growth of yttrium functionalized zinc oxide (YZO) nanorod arrays by hydrothermal. Curr. Appl. Phys. 2015, 15, S82-S88. [CrossRef]

22. Heo, S.; Kim, C.; Lee, B.; Lee, Y.; Lee, S.; Kim, D.Y. Effects of curing temperature on physical properties of hydrothermally-grown yttrium-doped ZnO nanorods. Curr. Appl. Phys. 2015, 15, 580-583. [CrossRef]

23. Heo, S.; Lee, Y.; Sharma, S.K.; Lee, S.; Kim, D.Y. Mole-controlled growth of Y-doped ZnO nanostructures by hydrothermal method. Curr. Appl. Phys. 2014, 14, 1576-1581. [CrossRef]

24. Lee, Y.; Lee, S. Large Memory Window and Tenacious Data Retention in (0001) ZnO:Cr Ferroelectric Memristive Device Prepared on (111) Pt Layer. J. Alloys Compd. 2017, 727, 304-310. [CrossRef]

25. Fang, M.; Liu, Z.W. Controllable Size and Photoluminescence of ZnO Nanorod Arrays on Si Substrate Prepared by Microwave-assisted Hydrothermal Method. Ceram. Int. 2017, 43, 6955-6962. [CrossRef]

26. Kim, C.; Lee, H.; Lee, B.; Lee, Y.; Lee, S.; Kim, D.Y. Effects of oxygen plasma pre-treatments on the characteristics of n-ZnO/p-Si heterojunction diodes. Curr. Appl. Phys. 2014, 14, 1380-1384. [CrossRef]

27. Lee, S.; Kim, D.Y. Characteristics of $\mathrm{ZnO} / \mathrm{GaN}$ heterostructure formed on GaN substrate by sputtering deposition of ZnO. Mat. Sci. Eng. B 2007, 137, 80-84. [CrossRef]

28. Lu, J.; Shi, Z.; Wang, Y.; Lin, Y.; Zhu, Q.; Tian, Z.; Dai, J.; Wang, S.; Xu, C. Plasmon-enhanced Electrically Light-emitting from ZnO Nanorod Arrays/p-GaN Heterostructure Devices. Sci. Rep. 2016, 6, 25645. [CrossRef] [PubMed]

29. Imai, M.; Watanabe, M.; Mochihara, A.; Tominaga, H.; Yoshino, K.; Shen, Q.; Toyoda, T.; Hayase, S. Atmospheric Growth of ZnO Films Deposited by Spray Pyrolysis using Diethylzinc Solution. J. Cryst. Growth 2017, 468, 473-476. [CrossRef]

30. Hsu, C.-L.; Su, I.L.; Hsueh, T.-J. Tunable Schottky contact humidity sensor based on S-doped ZnO nanowires on flexible PET substrate with piezotronic effect. J. Alloys Compd. 2017, 705, 722-733. [CrossRef]

31. Jacobs, C.B.; Maksov, A.B.; Muckley, E.S.; Collins, L.; Mahjouri-Samani, M.; Ievlev, A.; Rouleau, C.M.; Moon, J.-W.; Graham, D.E.; Sumpter, B.G.; et al. UV-activated ZnO Films on a Flexible Substrate for Room Temperature $\mathrm{O}_{2}$ and $\mathrm{H}_{2} \mathrm{O}$ Sensing. Sci. Rep. 2017, 7, 6053. [CrossRef] [PubMed]

32. Lee, Y.; Kim, D.Y.; Lee, S. Low-Power Graphene/ZnO Schottky UV Photodiodes with Enhanced Lateral Schottky Barrier Homogeneity. Nanomaterials 2019, 9, 799. [CrossRef]

33. Lee, H.; An, N.; Jeong, S.; Kang, S.; Kwon, S.; Lee, J.; Lee, Y.; Kim, D.Y.; Lee, S. Strong Dependence of Photocurrent on Illumination-Light Colors for ZnO/Graphene Schottky Diode. Curr. Appl. Phys. 2017, 17, 552-556. [CrossRef]

34. Lee, S.; Lee, Y.; Kim, D.Y.; Song, E.B.; Kim, S.M. Back-Gate Tuning of Schottky Barrier Height in Graphene/Zinc-Oxide Photodiodes. Appl. Phys. Lett. 2013, 102, 242114. [CrossRef] 
35. Cook, B.; Liu, Q.; Liu, J.; Gong, M.; Ewing, D.; Casper, M.; Stramel, A.; Wu, J. Facile Zinc Oxide Nanowire Growth on Graphene via a Hydrothermal Floating Method: Towards Debye Length Radius Nanowires for Ultraviolet Photodetection. J. Mater. Chem. C 2017, 5, 10087-10093. [CrossRef]

36. Sun, Y.; Wen, D. Conductance Quantization in Nonvolatile Resistive Switching Memory Based on the Polymer Composite of Zinc Oxide Nanoparticles. J. Phys. Chem. C 2018, 122, 10582-10591. [CrossRef]

37. Shih, C.-C.; Lee, W.-Y.; Chiu, Y.-C.; Hsu, H.-W.; Chang, H.-C.; Liu, C.-L.; Chen, W.-C. High Performance Transparent Transistor Memory Devices Using Nano-Floating Gate of Polymer/ZnO Nanocomposites. Sci. Rep. 2016, 6, 20129. [CrossRef]

38. Kim, S.-Y.; Hwang, J.; Kim, Y.J.; Hwang, H.J.; Son, M.; Revannath, N.; Ham, M.-H.; Cho, K.; Lee, B.H. Threshold Voltage Modulation of a Graphene-ZnO Barristor Using a Polymer Doping Process. Adv. Electron. Mater. 2019, 5, 1800805. [CrossRef]

39. Na, J.H.; Kitamura, M.; Arita, M.; Arakawa, Y. Dual Luminescence from Organic/Inorganic Hybrid p-n Junction Light-Emitting Diodes. Appl. Phys. Lett. 2009, 94, 213302. [CrossRef]

40. Zhan, Z.; Zheng, L.; Pan, Y.; Sun, G.; Li, L. Self-powered, visible-light photodetector based on thermally reduced graphene oxide-ZnO (rGO-ZnO) hybrid nanostructure. J. Mater. Chem. 2012, 22, 2589-2595. [CrossRef]

41. Rajamanickam, S.A.L.; Mohammad, S.M.; Hassan, Z. Effect of Substrates on Structural, Morphological, Optical and Electrical Characteristics on Poly (9,9-di-n-octylfluorenyl-2,7-diyl) (PFO) Thin Films. ECS J. Solid State Sci. Technol. 2020, 9, 026002. [CrossRef]

42. Palacios, R.; Formentin, P.; Martinez-Ferrero, E.; Pallarès, J.; Marsal, L.F. $\beta$-Phase Morphology in Ordered Poly(9,9-dioctylfluorene) Nanopillars by Template Wetting Method. Nanoscale Res. Lett. 2010, 6, 35. [CrossRef] [PubMed]

43. Chen, X.; Wan, H.; Li, H.; Cheng, F.; Nie, W.; Yao, B.; Xie, Z.; Wang, L.; Zhang, J. The Influence of Residue Aggregation in Solution on Photoluminescence and Electroluminescence of Polyoctylfluorene Thin Film. Org. Electron. 2012, 13, 475-482. [CrossRef]

44. Prins, P.; Grozema, F.C.; Nehls, B.S.; Farrell, T.; Scherf, U.; Siebbeles, L.D.A. Enhanced charge-carrier mobility in $\beta$-phase polyfluorene. Phys. Rev. B 2006, 74, 113203. [CrossRef]

45. Wadeasa, A.; Beegum, S.L.; Raja, S.; Nur, O.; Willander, M. The demonstration of hybrid n-ZnO nanorod/p-polymer heterojunction light emitting diodes on glass substrates. Appl. Phys. A 2009, 95, 807-812. [CrossRef]

46. Wadeasa, A.; Tzamalis, G.; Sehati, P.; Nur, O.; Fahlman, M.; Willander, M.; Berggren, M.; Crispin, X. Solution Processed ZnO Nanowires/Polyfluorene Heterojunctions for Large Area Lightening. Chem. Phys. Lett. 2010, 490, 200-204. [CrossRef]

47. Aleshin, A.N.; Shcherbakov, I.P. A light-emitting field-effect transistor based on a polyfluorene-ZnO nanoparticles film. J. Phys. D Appl. Phys. 2010, 43, 315104. [CrossRef]

48. Zaman, S.; Zainelabdin, A.; Amin, G.; Nur, O.; Willander, M. Influence of the polymer concentration on the electroluminescence of $\mathrm{ZnO}$ nanorod/polymer hybrid light emitting diodes. J. Appl. Phys. 2012, 112, 064324. [CrossRef]

49. Hasan, K.; Sandberg, M.O.; Nur, O.; Willander, M. ZnO/Polyfluorene Hybrid LED on an Efficient Hole-Transport Layer of Graphene Oxide and Transparent Graphene Electrode. Adv. Opt. Mater. 2014, 2, 326-330. [CrossRef]

50. Lin, Y.-Y.; Chen, C.-W.; Yen, W.-C.; Su, W.-F.; Ku, C.-H.; Wu, J.-J. Near-ultraviolet photodetector based on hybrid polymer/zinc oxide nanorods by low-temperature solution processes. Appl. Phys. Lett. 2008, 92, 233301. [CrossRef]

51. Guo, X.; Tang, L.; Xiang, J.; Ji, R.; Zhang, K.; Lai, S.K.; Zhao, J.; Kong, J.; Lau, S.P. Solution processable organic/inorganic hybrid ultraviolet photovoltaic detector. AIP Adv. 2016, 6, 055318. [CrossRef]

52. Azadinia, M.; Fathollahi, M.R.; Mosadegh, M.; Boroumand, F.A.; Mohajerani, E. Improved performance of photoconductive gain hybrid UV detector by trap state engineering of $\mathrm{ZnO}$ nanoparticles. J. Appl. Phys. 2017, 122, 154501. [CrossRef]

53. Kim, S.M.; Song, E.B.; Lee, S.; Zhu, J.; Seo, D.H.; Mecklenburg, M.; Seo, S.; Wang, K.L. Transparent and Flexible Graphene Charge-Trap Memory. ACS Nano 2012, 6, 7879-7884. [CrossRef]

54. Kim, Y.-J.; Hadiyawarman; Yoon, A.; Kim, M.; Yi, G.-C.; Liu, C. Hydrothermally grown ZnO nanostructures on few-layer graphene sheets. Nanotechnology 2011, 22, 245603. [CrossRef] 
55. Geng, W.; Zhao, X.; Liu, H.; Yao, X. Influence of Interface Structure on the Properties of ZnO/Graphene Composites: A Theoretical Study by Density Functional Theory Calculations. J. Phys. Chem. C 2013, 117, 10536-10544. [CrossRef]

56. Yu, Q.; Fu, W.; Yu, C.; Yang, H.; Wei, R.; Sui, Y.; Liu, S.; Liu, Z.; Li, M.; Wang, G. Structural, Electrical, and Optical Properties of Yttrium-Doped ZnO Thin Films Prepared by Sol-Gel Method. J. Phys. D Appl. Phys. 2007, 40, 5592. [CrossRef]

57. Sharma, B.K.; Khare, N.; Ahmad, S. A ZnO/PEDOT:PSS Based Inorganic/Organic Hetrojunction. Solid State Commun. 2009, 149, 771-774. [CrossRef]

58. Lee, B.; Kim, C.; Lee, Y.; Lee, S.; Kim, D.Y. Dependence of Photocurrent on UV Wavelength in $\mathrm{ZnO} / \mathrm{Pt}$ Bottom-Contact Schottky Diode. Curr. Appl. Phys. 2015, 15, 29-33. [CrossRef]

59. Hamel, L.-A.; Julien, M. Generalized demonstration of Ramo's theorem with space charge and polarization effects. Nucl. Instrum. Methods Phys. Res. Sect. A-Accel. Spectrom. Dect. Assoc. Equip. 2008, 597, 207-211. [CrossRef]

60. Zhang, H.; Babichev, A.V.; Jacopin, G.; Lavenus, P.; Julien, F.H.; Egorov, A.Y.; Zhang, J.; Pauporté, T.; Tchernycheva, M. Characterization and Modeling of a ZnO Nanowire Ultraviolet Photodetector with Graphene Transparent Contact. J. Appl. Phys. 2013, 114, 234505. [CrossRef]

61. Alam, M.J.; Murkute, P.; Ghadi, H.; Sushama, S.; Dwivedi, S.M.M.D.; Ghosh, A.; Ghosh, C.; Mondal, A.; Paul, S.; Mondal, S.; et al. Enhancing responsivity and detectivity in broadband UV-VIS photodetector by ex-situ UV-ozone annealing technique. Superlattices Microstruct. 2020, 137, 106333. [CrossRef]

62. Ji, C.H.; Kim, K.T.; Oh, S.Y. Correction: High-detectivity perovskite-based photodetector using a Zr-doped $\mathrm{TiO}_{\mathrm{x}}$ cathode interlayer. RSC Adv. 2019, 9, 40023. [CrossRef]

63. Sze, S.M. Physics of Semiconductor Devices, 3rd ed.; Wiley: New York, NY, USA, 2006.

(C) 2020 by the authors. Licensee MDPI, Basel, Switzerland. This article is an open access article distributed under the terms and conditions of the Creative Commons Attribution (CC BY) license (http://creativecommons.org/licenses/by/4.0/). 